\title{
The Application of Neural Networks for Prediction of Concentration of Harmful Components in the Exhaust Gases of Diesel Engines
}

\author{
Ivan GRUJIĆ, Nadica STOJANOVIĆ, Jovan DORIĆ, Danijela MILORADOVIĆ, Jasna GLIŠOVIĆ
}

\begin{abstract}
Means of transport (vehicles) are a part of everyday life. The main purpose of the vehicles is to transport the goods and the passengers. The road traffic has the largest share in transport. Majority of the transport vehicles use the IC engine as a power unit. The application of engines driven by fossil fuels has caused the road traffic to exhibit its poor side in terms of harmful effect on environment and human health. The constant tightening of the legal regulations has led the engine manufacturers to continuously improve the IC engines. Determination of the exhaust emission parameters usually requires an experiment. The possibility of neural network application for pollutants concentration prediction in the exhaust gases from diesel engines based on experimental data is considered in this paper. Some inputs, not previously considered in the reviewed literature, are introduced into the developed model of the neural network. By comparison with experimental data, it was established that the developed neural network model can successfully predict concentration of pollutants and that it can be used for future research.
\end{abstract}

Keywords: diesel engine; environment; legal regulations; road traffic; transport

\section{INTRODUCTION}

IC engines are dominantly applied as power units for road transport vehicles. Modern technology has not yet supplied a suitable alternative in terms of performance and overall energy efficiency, so they will be used as basic power units of transport means for a long time. Over one billion vehicles were registered worldwide, while their annual production exceeded 97 million units in 2017 [1].

The level of engagement of raw materials and energy resources in production and exploitation of vehicles is such that endangers the sustainability of further development of transport means. Particular problem is their negative ecological impact - toxic emissions, carbon dioxide emissions (greenhouse effect) and emissions of other toxic components that have an impact on the environment and human health (carbon monoxide, nitrogen oxides, particulate matters...).

According to data from 2015 (Fig. 1), the road transport sector is responsible for as much as $72.9 \%$ of total emissions related to the transport.

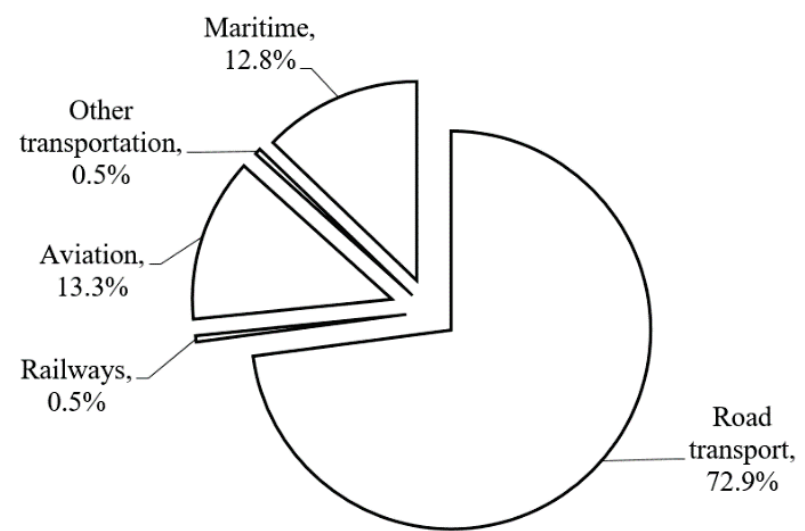

Figure 1 Emission of greenhouse gases within the European Union (EU) and its structure in the field of transport [2]

The economy and emission of IC engines are consequences of the work process characteristics, so the improvements in this domain have significant potential.

There is obvious need for the constant development of the IC engines, in order to reduce the concentration of pollutants in the exhaust gases. Technological development enables the increasing application of mathematical models, simultaneously reducing the number of experiments. Artificial neural networks (ANN) are the tools of modern technology, which can be considered as forms of artificial intelligence. Neural network models are convenient because they can predict some output quantity based on a certain number of inputs. They differ from the conventional methods of mathematical modelling and have the ability to learn about the system and to model it without prior knowledge on the functioning of the system. The prediction using a well-trained neural network is much faster than the simulation using conventional programs and mathematical models that usually require the solving of complex differential equations with numerical methods. However, the selection of the appropriate neural network is very important because it contributes to accuracy of the results. They are also convenient in reducing or increasing the number of inputs or outputs in order to increase accuracy of the results.

Predicting the emission of combustion products under different driving conditions is very important, especially in urban areas. For this reason, measurements were carried out in various driving cycles but emission is still very high. This is due to the inability to repeat the measurement results [3]. A large number of researchers have been engaged in predicting the engine performance and combustion products, based on a large experimental database. Tab. 1 shows the studies dealing with the prediction of exhaust emission parameters and/or engine performance parameters. The results shown are from research carried out on engines, which mainly use diesel fuel and rarely use a mixture of diesel and biodiesel fuels. It can be noted that the number of input parameters ranges from 2 to 5 , while the number of output parameters ranges from 1 to 10 . The number of working modes for which the values are recorded ranges from 7 to 15 .

The aim of application of the neural networks for prediction is based on the following: determination of the most influential parameters on the exhaust emission; determination of engine performance and determination of input parameters to obtain the most accurate values which would also be measured by the experiment. 
Furthermore, some of the studies were based on determination of the type of the neural networks or the training functions with which the values may be obtained that do not largely deviate from the experimental data.

Factors that influence air pollution exposures are [4]:

1. Traffic,

2. Infrastructure,

3. Meteorological conditions and

4. Geographical conditions.

Prognosis of carbon monoxide in the future [5] is necessary, because carbon monoxide is considered as silent and very deadly killer. The results obtained by ANN show that more efficient and accurate predictions could be provided, in order to take appropriate measures that can alleviate excessive carbon monoxide accumulation. By application of ANN, appropriate short-term measures for prevention or warning of air pollution can be developed, as well as reducing smoke and $\mathrm{NO}_{\mathrm{x}}[6]$.

By comparing the experimental results with the results obtained using neural networks, it was concluded that neural networks could be used to predict the exhaust emission parameters and engine performance.

Tab. 1 shows the input parameters that are mostly used by all authors, as well as those parameters that are found in only one of the research papers like fuel injection angle [7], inlet air temperature [8] and emulsified fuel percentages [9]. Unlike these three mentioned parameters, other input parameters are common for two, three or more research papers. Density, heat power and Cetane number are common for two papers $[10,11]$. The airflow, which is very important for the combustion process, is only considered as an input parameter in two papers $[12,13]$. The compression ratio is common for three studies [14-16]. The fuel injection pressure is associated with more research [17-20], as well as the injection timing $[14,16,17,19,21]$. In order to reduce harmful exhaust emission products, a mixture of diesel and biodiesel is used as fuel [10, 15, 16, 21-24]. The most common input parameters for all research papers were the engine speed and load.

Table $1 \mathrm{~A}$ review of input and output parameters of ANN from different research papers

\begin{tabular}{|c|c|c|c|c|c|c|c|c|c|c|c|c|c|c|c|c|c|}
\hline & \multicolumn{17}{|c|}{ mput paranters } \\
\hline Fuel injection angle & - & & & & & & & & & & & & & & & & \\
\hline Fuel injection pressure & $\bullet$ & & & & & & $\bullet$ & & & & & & & $\bullet$ & & $\bullet$ & \\
\hline Injection timing & $\bullet$ & & & - & & & & - & & & & & & $\bullet$ & - & & \\
\hline Speed (RPM) & $\bullet$ & & $\bullet$ & $\bullet$ & $\bullet$ & $\bullet$ & $\bullet$ & & - & $\bullet$ & $\bullet$ & & & & & - & $\bullet$ \\
\hline Biodiesel blend percentage & & $\bullet$ & $\bullet$ & $\bullet$ & $\bullet$ & & & & & $\bullet$ & & $\bullet$ & & & $\bullet$ & & \\
\hline Density & & $\bullet$ & & & & & & & & & & & & & & & $\bullet$ \\
\hline Heat power & & $\bullet$ & & & & & & & & & & & & & & & $\bullet$ \\
\hline Cetane number & & $\bullet$ & & & & & & & & & & & & & & & $\bullet$ \\
\hline Load & $\bullet$ & $\bullet$ & & $\bullet$ & & $\bullet$ & & - & & & $\bullet$ & $\bullet$ & - & $\bullet$ & - & & \\
\hline Fuel flow & & & & & & - & & $\bullet$ & - & & $\bullet$ & & & & & & \\
\hline Air flow & & & & & & $\bullet$ & & & & & $\bullet$ & & & & & & \\
\hline Compression ratio & & & & & & & & - & & & & - & & & - & & \\
\hline The temperature of the inlet air & & & & & & & & & - & & & & & & & & \\
\hline Emulsified fuel percentages & & & & & & & & & & & & & - & & & & \\
\hline & & & & & & & & utp & par & ete & & & & & & & \\
\hline Torque & & & - & & $\bullet$ & & - & & & $\bullet$ & - & & & & & - & • \\
\hline $\mathrm{HC}$ & $\bullet$ & $\bullet$ & $\bullet$ & $\bullet$ & $\bullet$ & & & & & $\bullet$ & & & $\bullet$ & $\bullet$ & & & \\
\hline $\mathrm{CO}$ & $\bullet$ & $\bullet$ & $\bullet$ & $\bullet$ & $\bullet$ & & & - & & $\bullet$ & & $\bullet$ & $\bullet$ & & & & $\bullet$ \\
\hline $\mathrm{CO}_{2}$ & - & & & - & $\bullet$ & & & & & & & & - & & & & \\
\hline $\mathrm{NO}_{\mathrm{x}}$ & - & - & & - & $\bullet$ & & & & - & & & - & - & - & & & $\bullet$ \\
\hline PM & $\bullet$ & & & $\bullet$ & $\bullet$ & & - & & & & & $\bullet$ & & $\bullet$ & & - & \\
\hline $\begin{array}{l}\text { Brake specific fuel consumption } \\
\text { (BSFC) }\end{array}$ & - & & - & & - & - & - & & & - & - & $\bullet$ & & & - & - & \\
\hline Exhaust gas temperature & & & & & $\bullet$ & & & & & & $\bullet$ & $\bullet$ & - & & - & & \\
\hline Brake thermal efficiency (BTE) & - & & & & & - & & & & & & $\bullet$ & & & $\bullet$ & & \\
\hline Brake power (BP) & & & & & - & $\bullet$ & & & & & & & & & & - & \\
\hline Excess air ratio coefficient & & & & & $\bullet$ & & & & & & & & & & & & \\
\hline Volumetric efficiency (VE) & & & & & & - & & & & & & & & & & & \\
\hline Brake mean effective pressure (BMEP) & & & & & & $\bullet$ & & & & & & & & & & & \\
\hline
\end{tabular}

Of course, the other methods for prediction of engine parameters exist. One such method is quasi-dimensional model [25]. The authors that have used this model are concluding that this model can be very useful and such can be used for future engine development.

The main objective of this paper is to develop a neural network model for prediction of concentration of harmful 
components $\left(\mathrm{CO}, \mathrm{CO}_{2}, \mathrm{NO}_{\mathrm{x}}, P M\right)$ in the exhaust gases of diesel engines. The uniqueness of the research presented in this paper is the fact that the input parameters are a combination of the engine operation indicators - indicated horse power, $P_{i}$, indicated thermal efficiency, $\eta_{i}$, and maximum amount of heat released during combustion, $I_{\max }$, which is the main difference between this study and the reviewed research in Tab. 1 . The parameters representing the operating conditions of the engine (engine speed, $n$, and engine load, $F$ ) are common for this study and other studies presented in Tab. 1. Excess air ratio coefficient (air factor), $\lambda$, is used as an additional input. The reason for this is the generally known fact that harmful components are formed as a product of the combustion process during which a mixture of fuel and air is burned, and therefore, this input can be a useful parameter that will contribute to the accuracy of the prediction.

\section{EXPERIMENTAL RESEARCH}

Required data for prediction of harmful components in exhaust gases must have real values. In addition, certain inputs are required for the $\mathrm{ANN}$, based on which the predictions will be made. Experimental research was carried out according to the European Stationary Cycle (ESC), shown in Fig. 2.

The ESC test cycle was introduced together with the ETC (European Transient Cycle) and the ELR (European Load Response) tests by the Euro III emission regulationDirective 1999/96/EC, effective year 2000-for emission measurement from heavy-duty diesel engines. The ESC is a 13-mode, steady-state procedure that replaced the R-49 test. Initially, the test was also referred to as OICA cycle or ACEA cycle [26].

The engine is tested on an engine dynamometer over a sequence of steady-state modes (Tab. 2, Fig. 2). The engine must be operated for the prescribed time in each mode, completing engine speed and load changes in the first 20 seconds. The specified speed shall be held to within $\pm 50 \mathrm{rpm}$ and the specified torque shall be held to within $\pm 2 \%$ of the maximum torque at the test speed. Emissions are measured during each mode and averaged over the cycle using a set of weighting factors. Particulate matter emissions are sampled on one filter over the 13 modes. The final emission results are expressed in $\mathrm{g} / \mathrm{kWh}$.

The $n_{h i}$ in the following equations was the highest engine speed, where $70 \%$ of the maximum power occurs, whereas, $n_{l o}$ was the lowest engine speed, where $50 \%$ of maximum power occurs respectively. The $n_{h i}$ and $n_{l o}$ were achieved by mapping the engine speed and power. The engine speeds $A, B$, and $C$ to be used during the test are then calculated from the following Eq. [26]:

$$
\begin{aligned}
& A=n_{l o}+0.25\left(n_{h i}-n_{l o}\right) \\
& B=n_{l o}+0.50\left(n_{h i}-n_{l o}\right) \\
& C=n_{l o}+0.75\left(n_{h i}-n_{l o}\right)
\end{aligned}
$$

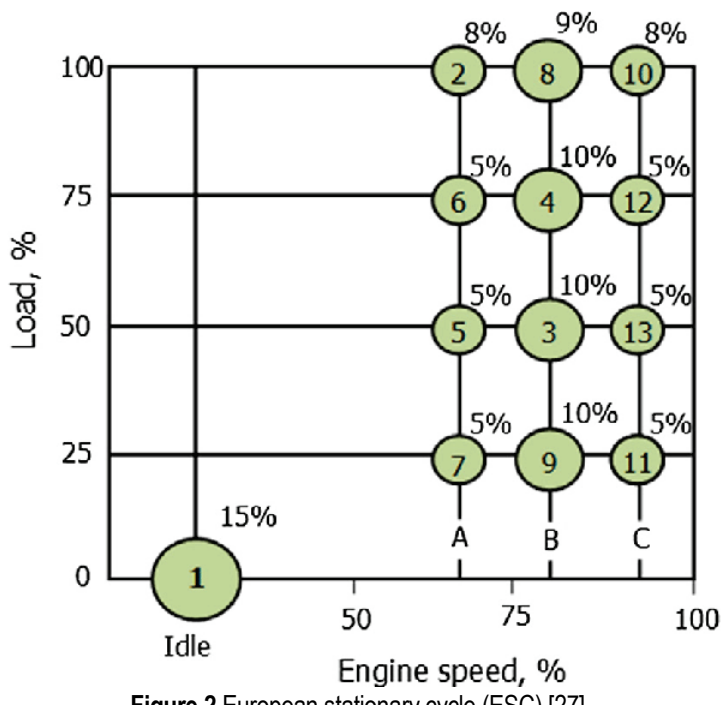

Figure 2 European stationary cycle (ESC) [27]

Table 2 ESC test modes [26]

\begin{tabular}{|c|c|c|c|c|}
\hline Mode & Engine Speed & $\begin{array}{c}\text { Load } \\
/ \%\end{array}$ & $\begin{array}{c}\text { Weight } \\
/ \%\end{array}$ & $\begin{array}{c}\text { Duration } \\
/ \text { min }\end{array}$ \\
\hline 1 & Low idle & 0 & 15 & 4 \\
\hline 2 & $A$ & 100 & 8 & 2 \\
\hline 3 & $B$ & 50 & 10 & 2 \\
\hline 4 & $B$ & 75 & 10 & 2 \\
\hline 5 & $A$ & 50 & 5 & 2 \\
\hline 6 & $A$ & 75 & 5 & 2 \\
\hline 7 & $A$ & 25 & 5 & 2 \\
\hline 8 & $B$ & 100 & 9 & 2 \\
\hline 9 & $B$ & 25 & 10 & 2 \\
\hline 10 & $C$ & 100 & 8 & 2 \\
\hline 11 & $C$ & 25 & 5 & 2 \\
\hline 12 & $C$ & 75 & 5 & 2 \\
\hline 13 & $C$ & 50 & 5 & 2 \\
\hline
\end{tabular}

An experimental diesel engine was used for experimental research. The specifications of the used engine are shown in Tab. 3.

Table 3 Engine characteristics

\begin{tabular}{|c|c|}
\hline Engine capacity & $454 \mathrm{~cm}^{3}$ \\
\hline Number of cylinders & 1 \\
\hline Cylinder bore / piston stroke & $85 \times 80 \mathrm{~mm}$ \\
\hline Compression ratio & $17.5: 1$ \\
\hline Maximum torque & $28.5 \mathrm{Nm}$ \\
\hline Maximum power & $7.3 \mathrm{~kW}$ \\
\hline RPM & $3000 \mathrm{~min}^{-1}$ \\
\hline
\end{tabular}

The measurements made during the final experiment were organized in such a way to obtain a sufficient number of parameters for determination of the indicated, effective and emission indexes of the engine. The measurement installation is shown in Fig. 3.

Smoke is a general term used to describe the cloudy, hazy emanations that result from the burning of organic substances. It consists of solid and/or liquid particles or droplets which are so small that they tend to remain suspended in the air for extended periods, varying from seconds to years. The smoke in the engine exhaust emission is a visible indicator of the combustion process of the engine. The smoke density determines the concentration of the particulate matter (PM). Diesel engine's smoke density is measured according to the BOSCH method [28]. 


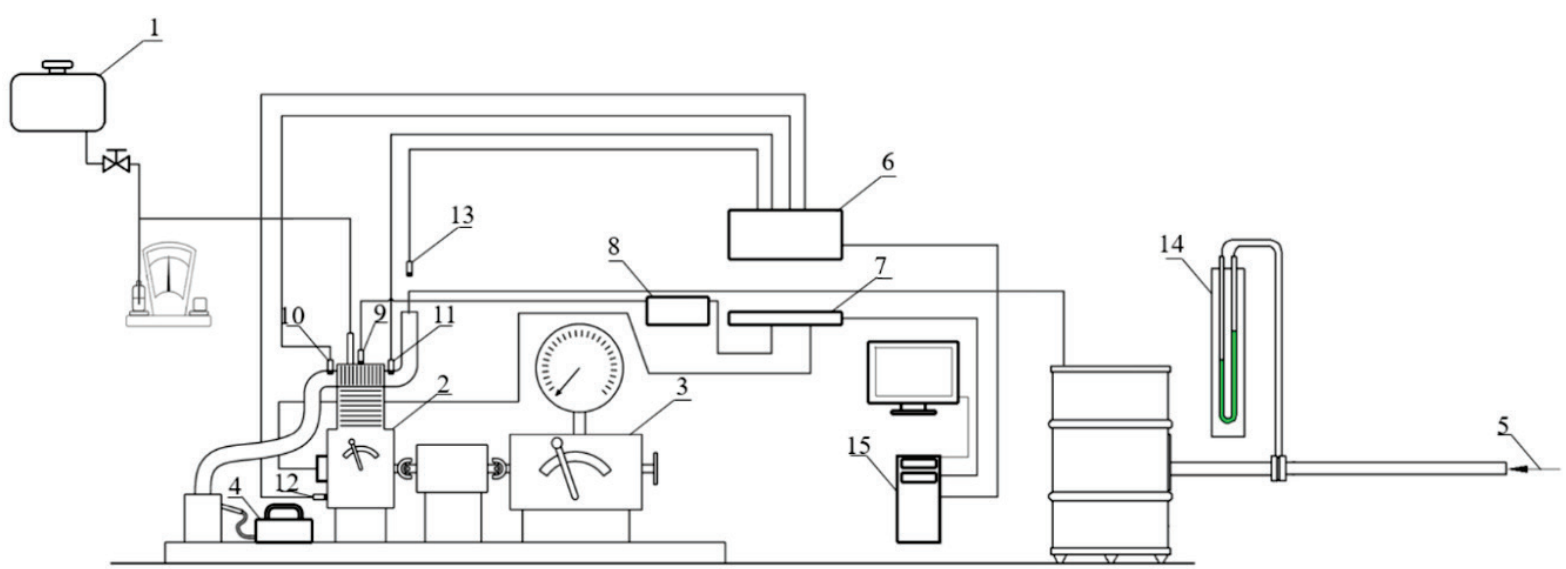

Figure 3 Measurement installation: 1 - Fuel tank; 2 - Engine; 3 - Dynamometer; 4 - AVL Ditest; 5 - Air flow; 6 - HBM UPM 60; 7 - AVL Indimer 619; 8 - Kistler 5007; 9 - Cylinder pressure sensor; 10 - Exhaust port temperature sensor; 11 - Intake port of temperature sensor; 12 - Oil temperature sensor; 13 - Environment temperature sensor; 14 - U manometer and 15 - PC

The experimental installation from Fig. 3 is equipped for recording of key parameters of engine operation. One part of the installation consists of equipment for recording the indicator parameters of the engine, i.e. for recording the engine cylinder pressure. The second part of the installation consists of equipment for engine load that is used for determination of engine effective parameters. Of course, as the additional parts of the measuring installation, there are fuel and air measurement equipment as well as exhaust emission measurement equipment, which is crucial for the rest of the work, or more accurate for ANN analysis.

The calculation of PM emission is based on correlation between the exhaust gas smoke density and the concentration of the PM. The generally accepted correlation (4) of the Motor Industry Research Association (MIRA) is used:

$$
P M_{\text {conc }}=982 \cdot B S N \cdot 10^{(B S N \cdot 0.1272-1.66)}
$$

where: $P M_{\text {conc }}, \mathrm{mg} / \mathrm{m}^{3}$ is concentration of $\mathrm{PM} ; B S N(-)$ is exhaust gas smoke density according to $\mathrm{BOSCH}$ method (BOSCH smoke number), which is valid for the following conditions: exhaust gas pressure $p_{\text {eg }}=101.3 \mathrm{kPa}$; exhaust gas temperature $T_{\text {eg }}=298 \mathrm{~K}$ and density of exhaust gases $\rho_{\mathrm{eg}}=1.293 \mathrm{~kg} / \mathrm{m}^{3}$.
Mass emission of $P M$ under conditions prescribed for exhaust gases, $P M_{\text {mass, }}$, is calculated using Eq. (5).

$$
P M_{\text {mass }}=\frac{1}{1.293 \cdot 10^{-3}} \cdot P M_{\text {conc }}
$$

Specific emission of $P M, P M_{\mathrm{e}}$, is calculated using expression (6):

$$
P M_{\mathrm{e}}=\frac{\sum_{i=1}^{13} P M_{\mathrm{mass}} \cdot W F_{i}}{\sum_{i=1}^{13} P(n)_{i} \cdot W F_{i}}
$$

where: $W F i$ are prescribed impact factors (Tab. 4) and $P(n)_{i}$ are power for the proper mode.

Table 4 Prescribed impact factors $W F_{i}$
\begin{tabular}{|l|c|c|c|c|c|c|c|}
\hline Mode & 1 & 2 & 3 & 4 & 5 & 6 & 7 \\
\hline$W F_{i}$ & 0.15 & 0.08 & 0.10 & 0.10 & 0.05 & 0.05 & 0.05 \\
\hline Mode & 8 & 9 & 10 & 11 & 12 & 13 & \\
\cline { 2 - 6 } & 0.09 & 0.10 & 0.08 & 0.05 & 0.05 & 0.05 & \\
\hline
\end{tabular}

Table 5 Input data needed to form a neural network model

\begin{tabular}{|c|c|c|c|c|c|c|c|c|c|}
\hline \multicolumn{9}{|c|}{ Inputs of neural network } & \multicolumn{5}{c|}{ Harmful products concentration } \\
\hline$n / \mathrm{min}^{-1}$ & $F / \mathrm{N}$ & $\lambda /-$ & $I_{\max } / \mathrm{kJ} / \mathrm{m}^{3}$ & $P_{i} / \mathrm{kW}$ & $\eta_{i} /-$ & $\mathrm{CO} / \%$ & $\mathrm{CO}_{2} / \%$ & $\mathrm{NO}_{x} / \mathrm{ppm}$ & $P M_{\mathrm{e}} / \mathrm{g} / \mathrm{kWh}$ \\
\hline 1020 & 0.8 & 7.189 & 274.8 & 0.455 & 0.271 & 0.09 & 1.7 & 103 & 0.180283 \\
\hline 1961 & 29.1 & 1.797 & 1411.3 & 5.394 & 0.419 & 0.1 & 8 & 1132 & 0.746608 \\
\hline 2328 & 14.7 & 2.765 & 900 & 3.902 & 0.435 & 0.04 & 4.9 & 365 & 0.282031 \\
\hline 2339 & 21.7 & 2.054 & 1231 & 5.363 & 0.443 & 0.06 & 6.2 & 630 & 0.546795 \\
\hline 1964 & 14.4 & 3.144 & 851.5 & 3.121 & 0.425 & 0.03 & 4 & 533 & 0.208045 \\
\hline 1956 & 21.5 & 2.355 & 1150 & 4.277 & 0.440 & 0.03 & 5.6 & 845 & 0.629642 \\
\hline 1960 & 7.2 & 4.602 & 597.6 & 2.002 & 0.399 & 0.03 & 2.5 & 277 & 0.171794 \\
\hline 2340 & 29.3 & 1.424 & 1479 & 6.693 & 0.387 & 0.51 & 9 & 786 & 2.749162 \\
\hline 2330 & 7.1 & 4.147 & 628.6 & 2.398 & 0.404 & 0.05 & 2.8 & 220 & 0.250592 \\
\hline 2674 & 28.7 & 1.345 & 1660 & 7.709 & 0.374 & 0.79 & 10.5 & 700 & 2.825722 \\
\hline 2674 & 7.2 & 3.718 & 670 & 2.893 & 0.390 & 0.09 & 3.9 & 145 & 0.420308 \\
\hline 2683 & 21.6 & 1.909 & 1276.4 & 6.040 & 0.412 & 0.18 & 7.6 & 580 & 0.586758 \\
\hline 2657 & 14.3 & 2.592 & 965 & 4.353 & 0.408 & 0.1 & 5.1 & 275 & 0.443567 \\
\hline
\end{tabular}

The input values and values of the harmful combustion products concentration necessary for the modelling of the neural network were obtained using the previously described measurement installation and the above expressions. Parameter values can be seen in Tab. 5 . 


\section{NEURAL NETWORK MODEL}

The ESC engine test cycle consists of 13 modes, one of which is the idle mode of the engine. Consequently, the number of samples entered as inputs and desired output values of the neural network is relatively small. An optimal neural network model has been found that provides the most accurate results by numerous testing of different neural network architectures (with different numbers of hidden neurons, different numbers of hidden layers, different training algorithms, etc.). The developed neural network model has one hidden layer and 6 neurons in the hidden layer (Fig. 4) and it uses the Bayesian regularization training algorithm. This training algorithm was chosen because it is very suitable for small data samples, as in this case. Another reason for selecting the above- mentioned training algorithm is specificity of the output values of the components for individual modes. Samples used for training, testing and validation are very important parameters for the results of the ANN. The percentages of the values chosen for those parameters are: $60 \%$ of samples are taken for training, $20 \%$ for testing and $20 \%$ for validation (more accurate: 7 samples for training, 3 samples for testing and 3 samples for validation). It is important to say that the other combinations of those parameters were also tested, but this one has given the best results.

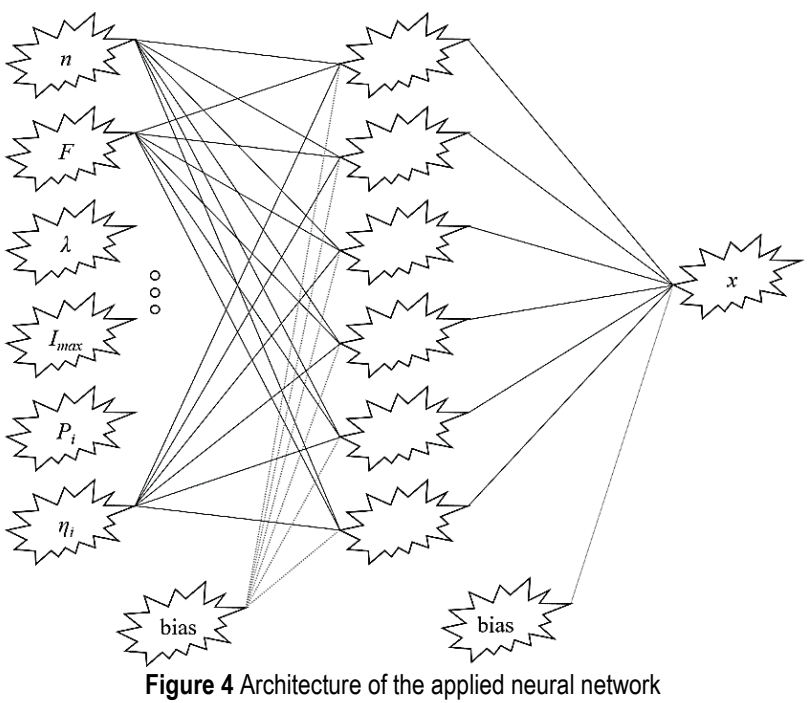

From Tab. 5, it can be seen that the CO concentration has similar values for each mode, i.e. it is stable. Unlike this component, other components have extremely rapid changes in values in different operating modes. Therefore, the problem arises in the prediction. However, unlike other components, $\mathrm{CO}$ cannot be considered as very dangerous pollutant, which means that its prediction is not as significant as the prediction of other toxic components.

The neural network, Fig. 4, has six inputs. However, although prediction of four components is performed, the developed neural network model has only one output. Identical network architecture was used to predict each toxic component, with only the output being changed, i.e. the value of the toxic component which prediction is performed. Of course, during the development of the most suitable prediction model, the possibilities for the neural network to have multiple outputs were tested (combination of all four components, as well as individual components). Unfortunately, such an approach has given poor results and was rejected as such.

Similar research can be found in the literature [28, 29]. However, in contrast from the mentioned research, in this paper we have significant differences which make this paper unique in relation to the above-mentioned works. In the study [29], two different neuronal architectures were used. In the first architecture, 4 constant inputs were used, while 5 inputs were changed in order to obtain the best possible results. Also, only the $\mathrm{CO}$ was used as the output parameter. In the other architecture there are 9 inputs with the same output as in the previous architecture. The research [30] is similar to the previous research according to the application of the architecture of the neural network, but only for the first case. The difference is that in this research there are two outputs $\mathrm{CO}$ and PM. Unlike the previous mentioned papers, in this paper, a different architecture of the neural network was used with some different inputs, added outputs and with different number of neurons in hidden layer. The same inputs were always used without adding a new one. One output for each of the components of the exhaust gases has always been applied.

The ANN is widely used, and it can be applied in all scientific fields. Concretely, for engines, it can be used for exhaust emission prediction, but also for engine control, for reduction of fuel consumption, as well as for reduction of the cylinder temperature, with the purpose of $\mathrm{NOx}$ reduction. The use of ANN has very good qualities, because it can enable up to 3000 times faster engine data calculation, with respect to conventional numerical analyses [31].

\section{RESULTS AND DISCUSSION}

The application of neural networks (Figs. 5 to 8) leads to obtaining the extremely high accuracy, which can be seen from the value of $R^{2}$, which is about 0.999 .

Results of the modelling were compared with experimentally obtained data in order to determine whether it is possible to apply ANN for emission prediction based on the inputs used. The use of a small number of input data for prediction of the exhaust emission parameters was also one of the challenges. The comparisons between the measured and the predicted values are presented in Figs. 5 to 8 .

In general, despite the small number of input data and the rapid changes in values of the individual exhaust emission parameters, the obtained results match experimental results with great accuracy, Tab. 6. Some authors have come to the conclusion that if the experiments are producing steady results (i.e. repeating an experiment under the same conditions produces almost the same result), the usage of ANNs may be highly recommended. However, in some cases (like the case of $\% \mathrm{~N}$ ), due to the complexity of combustion operation, the ANN may not get similar results even under the same experimental conditions [32]. In such cases, the usage of neural networks may not be appropriate. In order to train a neural network, there must be either a logical linear relation or a logical non-linear relation between the input and the output.

Figs. 5 to 8 illustrate the plots of the network prediction for exhaust and their deviations from measured values. The 
mean error of the predicted values was in the range of $0.08 \%$ to $1.22 \%$. The smallest value of mean error was found for $\mathrm{CO}$ and the highest was found for $\mathrm{CO}_{2}$. For $\mathrm{CO}$ this is expected because variations in $\mathrm{CO}$ values from between regimes are very small.
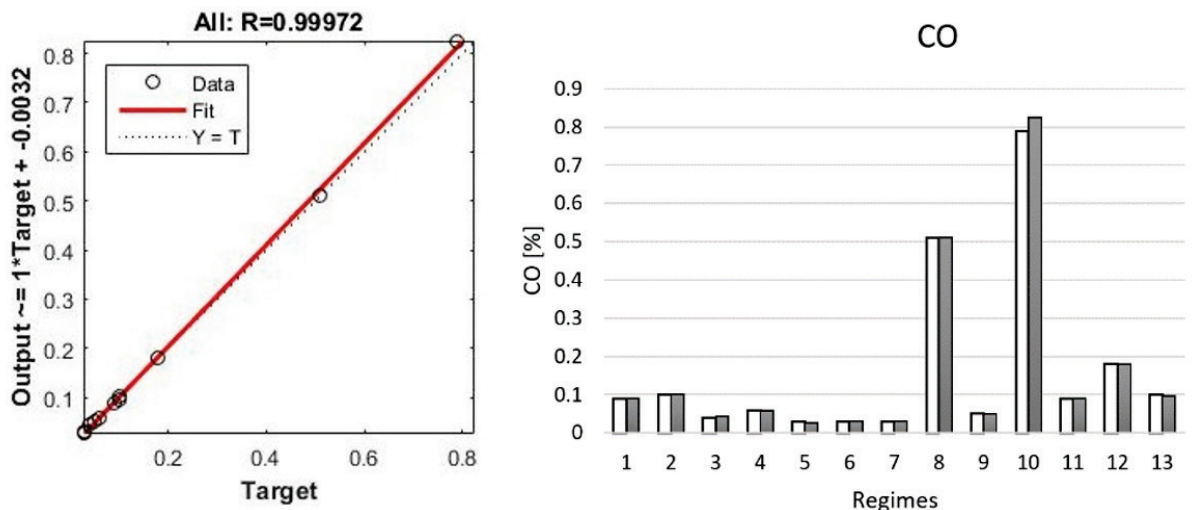

口Experimental

$\square$ Predicted

Figure 5 Correlation coefficients for $\mathrm{CO}$ prediction and comparison between measured and predicted values

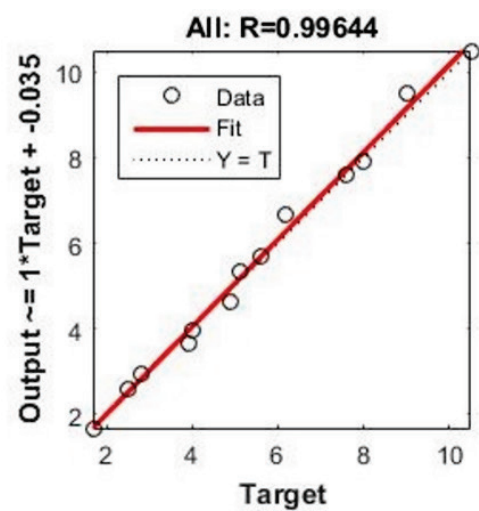

$\mathrm{CO} 2$

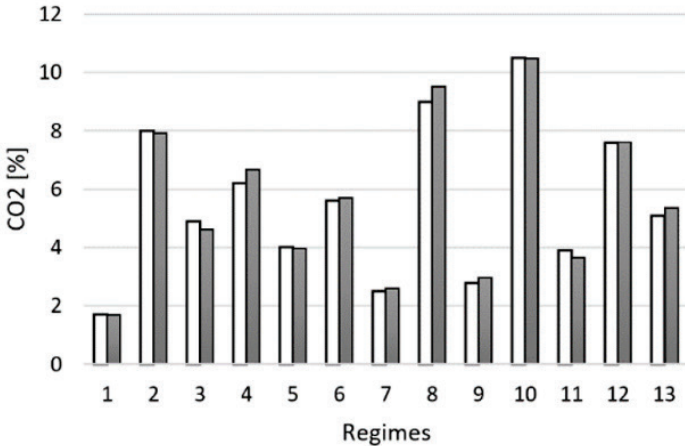

口Experimental 口Predicted

Figure 6 Correlation coefficients for $\mathrm{CO}_{2}$ prediction and comparison between measured and predicted values
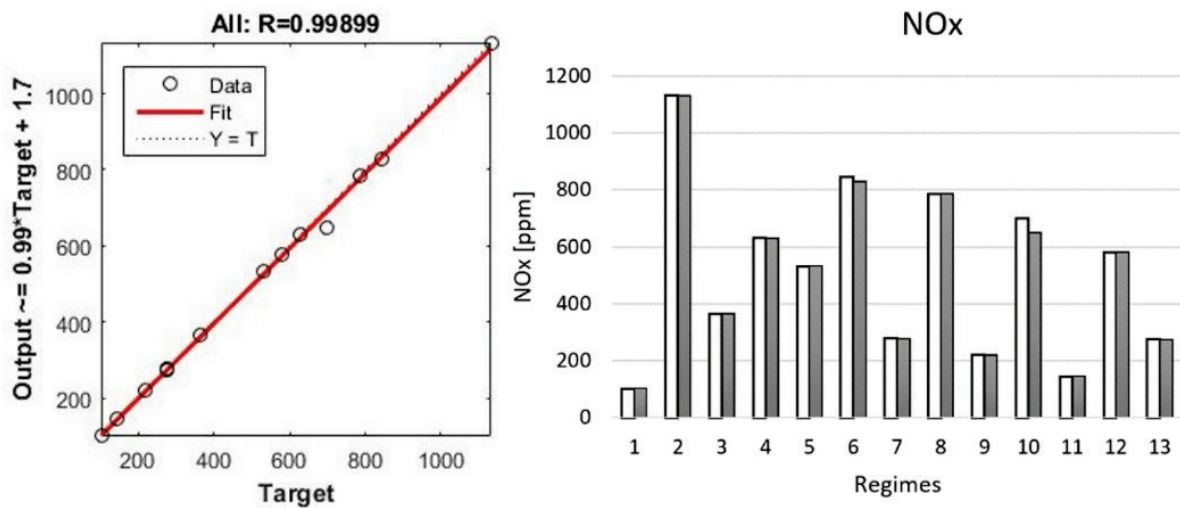

口Experimental $\square$ Predicted

Figure 7 Correlation coefficients for NOx prediction and comparison between measured and predicted values

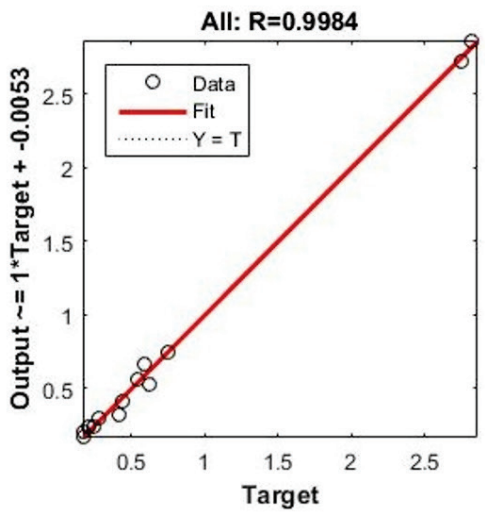

PMe

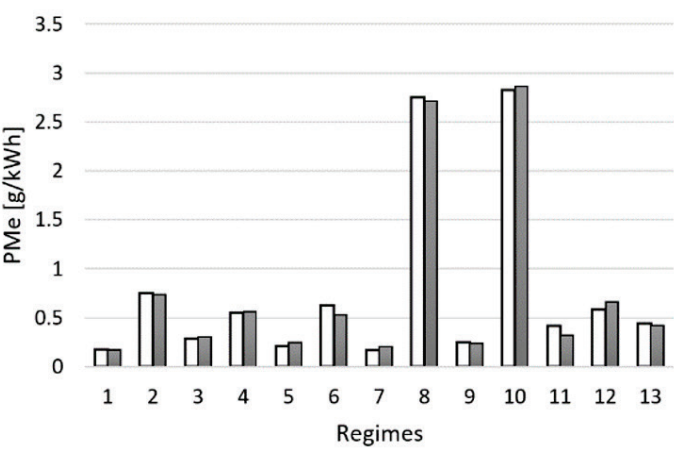

DExperimental $\square$ Predicted

Figure 8 Correlation coefficients for $P M_{\mathrm{e}}$ prediction and comparison between measured and predicted values 
The criterion followed for the architecture choice was the highest averaged $R^{2}$ obtained. The resulting ANN architectures selected for exhaust components was network with 6 neurons. The highest value for the $R^{2}$ is obtained during the prediction of $\mathrm{CO}$ and it is 0.99972 , and the lowest value is registered for $\mathrm{CO}_{2}$. This corresponds to the earlier mentioned mean error.

Taking into account that all the mean errors are below $2 \%$, the applied neural network architecture is giving very acceptable results. From Figs. 5 to 8 , this can also be visually confirmed by observing variations between experimental and predicted values.

Table 6 The mean error of the data obtained by ANN compared to the experimental data

\begin{tabular}{|l|c|c|c|c|}
\hline Exhaust emission component & $\mathrm{CO}$ & $\mathrm{CO}_{2}$ & $\mathrm{NO}_{\mathrm{x}}$ & $P M_{\mathrm{e}}$ \\
\hline Mean error, [\%] & 0.08 & 1.22 & 0.71 & 0.53 \\
\hline
\end{tabular}

By comparing obtained results with previous research $[28,29]$, it can be concluded that the results obtained are significantly better in terms of error compared to experimental results. It can be said that a positive result has been achieved, that is, with the application of a small number of data and a small number of neurons in the hidden layer, a very good accuracy has been achieved, which can be confirmed by values of errors in Tab. 6 .

It is found that the obtained model of ANN has given good results for a small number of samples. The main reason for this is the applied training algorithm. The same algorithm was used in the research where also the small number of samples is used and values of the errors were from 0.075 to 2.649 [33].

\section{CONCLUSION}

Ecology has been one of the most current topics for many years. Of course, this is not without a good reason. The consequences of the Earth pollution can be seen everywhere. Motor vehicles are considered as one of the biggest polluters, but they also represent a necessary part of everyday life. It is disputable whether this fact is completely accurate as far as pollution is concerned, but their impact can by no means be ignored.

Engine is the primary source of pollution from motor vehicles. The formation of harmful substances is a consequence of the combustion process that is crucial for the engine's operation. In order to determine the concentration of harmful components in the exhaust gases of the engine, an experiment is generally used. However, any experimental research entails time, costs, and environmental pollution. The development of artificial intelligence provides a more elegant approach that requires less time and money.

The main purpose of this paper was to examine whether it is possible to predict the concentration of harmful components by using neural networks with inputs which have not been applied in earlier research and which are directly related to the combustion process. Despite the small number of data and the rapid changes in values, the developed neural network model made a prediction with great accuracy. Of course, the prediction is not the most important. The most important is to see whether it is possible to apply neural networks for the determination of exhaust emission concentration. Further research can be based on determination of the most influential parameter on the exhaust emission. If something like this could be accomplished, optimization of the combustion process could be undertaken, and harmful components would be reduced.

\section{Acknowledgement}

This paper was realized within the framework of the project "The research of vehicle safety as part of a cybernetic system: Driver-Vehicle-Environment", ref. no. TR35041, funded by the Ministry of Education, Science and Technological Development of the Republic of Serbia.

\section{REFERENCES}

[1] See http://www.oica.net/category/production-statistics/2017 -statistics/

[2] Seehttps://www.eea.europa.eu/data-and-maps/indicators/ transport-emissions-of-greenhouse-gases/transportemissions-of-greenhouse-gases-10

[3] Lacour, S., Joumard R., \& André M. (2001). Exploring ways to improve instantaneous emission models for passenger cars. International Journal Vehicle Design, 27(1-4), 76-85. https://doi.org/10.1504/IJVD.2001.001953

[4] Cai, M., Yin, Y., \& Xie, M. (2009). Prediction of hourly air pollutant concentrations near urban arterials using artificial neural network approach. Transportation Research Part D, 14(1), 32-41. https://doi.org/10.1016/j.trd.2008.10.004

[5] Nigam, S., Nigam, R., \& Kapoor, S. (2013). Forecasting carbon monoxide concentration using artificial neural network modelling. Proceedings of the International Conference on Current Trends in Advanced Computing ICCTAC 2013, 15-16 February 2013, Bangalore, India, 3540.

[6] Bose, N. \& Raghavan, I. (2005). Prediction of emissions using combustion parameters in a diesel engine fitted with ceramic foam diesel particulate filter through artificial neural network techniques. International Journal of Automotive Technology, 6(2), 95-105.

[7] Gruden, D. (2012) Power units for future- quo vadis? MVM - International Journal for Vehicle Mechanics, 38(3), 7-26. https://doi.org/10.1504/IJVD.2001.001953

[8] Mohammadhassani, J., Khalilarya, Sh., Solimanpur, M., \& Dadvand, A. (2012). Prediction of NOx Emissions froma Direct Injection Diesel Engine Using Artificial Neural Network. Modelling and Simulation in Engineering, 2012(12), 1-9. https://doi.org/10.1155/2012/830365

[9] Kökkülünk, G., Akdoğan, E., \& Ayhan, V. (2013). Prediction of emissions and exhaust temperature for direct injection diesel engine with emulsified fuel using ANN. Turkish Journal of Electrical Engineering \& Computer Sciences, 21(2), 2141-2152. https://doi.org/10.3906/elk-1202-24

[10] Manjunatha, R., Badari Narayana, P., \& Hema Chandra Reddy, K. (2010). Application of Artificial Neural Networks for Emission Modelling of Biodiesels for a C.I Engine under Varying Operating Conditions. Modern Applied Science, 4(3), 77-89. https://doi.org/10.5539/mas.v4n3p77

[11] Tosun, E., Aydin, K., \& Bilgili, M. (2016). Comparison of linear regression and artificial neural network model of a diesel engine fueled with biodiesel-alcohol mixtures. Alexandria Engineering Journal, 55(4), 3081-3089. https://doi.org/10.1016/j.aej.2016.08.011

[12] Boruah, D., Thakur, P. K., \& Baruah, D. (2016). Artificial Neural Network based Modelling of Internal Combustion Engine Performance. International Journal of Engineering Research \& Technology (IJERT), 5(3), 569-576. 
https://doi.org/10.17577/IJERTV5IS030924

[13] Mohd Noor, C. W., Mamat, R., Najafi, G., Mat Yasin, M. H., Ihsan, K., \& Noor, M. M. (2016). Prediction of marine diesel engine performance by using artificial neural network mode. Journal of Mechanical Engineering and Sciences, 10(1), 1917-1930. https://doi.org/10.15282/jmes.10.1.2016.15.0183

[14] Chatterjee, A. \& Dutta, R. K. (2016). Prediction of CO emission from I. C. Engines using Back Propagation Neural Network. IOSR Journal of Mechanical and Civil Engineering (IOSR-JMCE), 13(3), 105-111. https://doi.org/10.9790/1684-130305105111

[15] Shiva, K., Srinivas Pai, P., Shrinivasa Rao, B. R., \& Samaga, B. S. (2010). Performance and emission characteristics of a 4 stroke C.I. Engine operated on honge methyl ester using artificial neural network. ARPN Journal of Engineering and Applied Science, 5(6), 83-94.

[16] Shiva, K., Srinivas Pai, P., \& Shrinivasa Rao, B. R. (2013). Influence of injection timings on performance and emissions of a biodiesel engine operated on blends of Honge methyl ester and prediction using artificial neural network. Journal of Mechanical Engineering Research, 5(1), 5-20. https://doi.org/10.5897/JMER12.057

[17] Garg, A. B., Diwan, P., \& Saxena, M. (2012). Artificial Neural Networks for Internal Combustion Engine Performance and Emission Analysis. International Journal of Computer Applications, 87(6), 23-27. https://doi.org/10.5120/15212-3705

[18] Sekmen, Y., Gölcü, M., Erduranll, P., \& Pancar, Y. (2006) Prediction of performance and smoke emission using artificial neural network in a diesel engine. Mathematical and Computational Applications, 11(3), 205-214.

[19] Ganapathy, T., Gakkhar, P. R., \& Murugesan, K. (2009). Artificial neural network modeling of Jatropha oil fueled diesel engine for emission predictions. Thermal Science, 13(3), 91-102. https://doi.org/10.2298/TSCI0903091G

[20] Akcayol, M. A., Çınar, C., Bulbul, H. I., \& Kilicarsalan, A. (2004). Artificial Neural Network Based Modeling of Injection Pressure in Diesel Engines. Proceedings of the 4th WSEAS International Conference on Information Science, Communications and Applications, 21 - 23 April 2004, Miami, Florida.

[21] Prasad, T. H., Reddy, H. C. K., \& Rao, M. M. (2010) Performance and exhaust emissions analysis of a diesel engine using methyl esters of fish oil with artificial neural network aid. IACSIT International Journal of Engineering and Technology, 2(1), 23-27.

[22] Ghobadian, B., Rahimi, H., Nikbakht, A. M., Najafi, G., \& Yusaf, T. F. (2009). Diesel engine performance and exhaust emission analysis using waste cooking biodiesel fuel with an artificial neural network. Renewable Energy, 34, 976-982. https://doi.org/10.1016/j.renene.2008.08.008

[23] Jafarmadar, S. (2015). A comparative analysis of two neural network predictions for performance and emissions in a biodiesel fueled diesel engine. International Journal of Automotive Engineering, 5(2), 999-1008.

[24] Najafi, G., Ghobadian, B., Yusaf, T. F., \& Rahimi, H. (2007). Combustion analysis of a $\mathrm{CI}$ engine performance using waste cooking biodiesel fuel with an artificial neural network aid. American Journal of Applied Sciences, 4(10), 756-764. https://doi.org/10.3844/ajassp.2007.759.767

[25] Bukovac, O., Medica, V., \& Mrzljak, V. (2017). Quasidimensional diesel engine model with direct calculation of cylinder temperature and pressure. Technical Gazette, 24(3), 681-686. https://doi.org/10.17559/TV-20151116115801

[26] See https://www.dieselnet.com/standards/cycles/esc.php

[27] Nabi, M. N., Zare, A., Hossain, F. M., Rahman, M. M., Bodisco, T. A., Ristovski, Z. D., \& Brown, R. J. (2016) Influence of fuel-borne oxygen on European Stationary Cycle: Diesel engine performance and emissions with a special emphasis on particulate and $\mathrm{NO}$ emissions, Energy Conversion and Management, 127, 187-198. https://doi.org/10.1016/j.enconman.2016.09.010

[28] Robert Bosch AG. (1986). Automotive Handbook. $2^{\text {nd }}$ Edition, Stuttgart, Germany.

[29] Grujić, I., Davinić, A., Stojanović, N., Glišović, J., \& Miloradović, D. (2017). Determination of influence parameters on concentration of carbon monoxide in exhaust gases by using artificial neural networks (ANN). Tractors and power machines, 22(1/2), 58-65.

[30] Grujic, I., Davinic, A., Stojanovic, N., Glisovic, J., Pesic, R., \& Narayan, S. (2018). Application of ANN for determination influence parameters on the concentration of NOx and PM in exhaust gases of a diesel engine. Mezdunarodna konferencija "EKO VARNA" 2018, Varna, 14-16 June, 1320.

[31] Bukovac, O., Medica, V., \& Mrzljak, V. (2015). Steady state performances analysis of modern marine two-stroke low speed diesel engine using MLP neural network model, Shipbuilding, 66(4), 57-70.

[32] Arcaklioglu, E. \& Çelikten, I. (2004). A diesel engine's performance and exhaust emissions. Applied Energy, 80(1), 11-22. https://doi.org/10.1016/j.apenergy.2004.03.004

[33] Kayabasi, A. \& Akadagli, A. (2016). An application of ann model with bayesian regularization learning algorithm for computing the operating frequency of c-shaped patch antennas. Advances in Science, Technology and Engineering Systems Journal, 1(5), 1-5.

\section{Contact information:}

Ivan GRUJIĆ, Assistant MSC

University of Kragujevac, Faculty of Engineering

Sestre Janjic 6, 34000 Kragujevac, Serbia

E-mail: ivan.grujic@kg.ac.rs

Nadica STOJANOVIĆ, Assistant MSc

(Corresponding author)

University of Kragujevac, Faculty of Engineering

Sestre Janjic 6, 34000 Kragujevac, Serbia

E-mail: nadica.stojanovic@kg.ac.rs

Jovan DORIĆ, Associate Professor, PhD

University of Novi Sad, Faculty of Technical Sciences

Trg Dositeja Obradovića 6, 21001 Novi Sad, Serbia

E-mail: jovan_d@uns.ac.rs

Danijela MILORADOVIĆ, Associate Professor, PhD

University of Kragujevac, Faculty of Engineering

Sestre Janjic 6, 34000 Kragujevac, Serbia

E-mail: neja@kg.ac.rs

Jasna GLIŠOVIĆ, Associate Professor, PhD University of Kragujevac, Faculty of Engineering

Sestre Janjic 6, 34000 Kragujevac, Serbia

E-mail: jaca@kg.ac.rs 